\title{
Market Segmentation of Pennslyvania Floral Consumers by Purchase Volume and Primary Retail Outlet
}

\author{
Bridget K. Behe' and Dennis J. Wolnick ${ }^{2}$ \\ Department of Horticulture, The Pennsylvania State University, \\ University Park PA 16802
}

Additional index words. marketing, discriminant analysis, consumer behavior

\begin{abstract}
Market segmentation is an, efficient method of defining consumer groups to develop new markets. The purpose of this research was to determine the viability of market segmentation strategies based on volume and location of purchase. A sample of 401 Pennsylvania floral consumers was divided into groups based on the number and the primary location of floral purchases. Two discriminant analyses were conducted to determine differences between market segments. Heavy floral consumers exhibited a higher level of floral knowledge, purchased more floral products for themselves and from nonflorist retailers, and had higher incomes than light or medium floral users. Florist customers purchased fresh flowers more frequently, bought more floral gifts, and spent a higher amount per purchase than supermarket customers. Segmentation based on volume of purchase and primary retail location are both viable alternatives for market development strategies for floral consumers.
\end{abstract}

Marketing theory states that it is easier to have a current consumer make an additional purchase than to obtain a new consumer. Volume segmentation is the process of dividing a consumer market on the basis of purchase frequency and has been used successfully in various markets (Kotler, 1984). Thus, increasing the number of purchases per consumer is an efficient marketing strategy.

Compared with other floral consumer markets, supermarket customers have been surveyed and profiled more often (Behe, 1985; Goldsberry et al., 1985; Kelly, 1983; Kiplinger and Sherman, 1962; Miller, 1977; Robertson and Hahn, 1978; Zawadzki et al., 1960). Behe (1985) divided the market of supermarket floral customers into five segments. "Friendly Buyers" were young consumers with relatively low household incomes who purchased flowers as gifts for their mothers and co-workers, but made few purchases for themselves. "Married Men" were somewhat older and purchased flowers as gifts for their wives. "Selfers," the largest segment, purchased flowers frequently for their personal use; price was very important to them. "Annuals" were consumers who purchased flowers once each year, usually from supermarkets, and used flowers for home decoration, The "Educated Mothers" segment was comprised of older, upper-income women who bought floral products mainly

Received for publication 8 Dec. 1989. The authors thank the Pennsylvania Florist's Assn. for their generous funding of this research. The cost of publishing this paper was defrayed in part by the payment of page charges. Under postal regulations, this paper therefore must be hereby marked advertisement solely to indicate this fact.

'Assistant Professor. Current address: Dept. of Horticulture, Auburn Univ., Auburn, AL 368495408.

Associate Professor. at holidays for meals: Thanksgiving, Easter, and Christmas.

These consumer segments were similar to five consumer segments identified in a study of floral consumers conducted by Market Facts (1985). They used a panel of men and women and identified five consumer segments: Plant People, Flower People, Givers, Selfers, and Special Occasion Only. Women in this study were more price-sensitive than men.

The purpose of our study was to determine whether differences exist between floral consumer market segments based on: 1) the number of floral purchases and 2) the primary location of purchases. If the groups were from different populations, specific and separate marketing strategies might be employed to better meet the distinct needs of these groups. If not, markets could be developed using a homogeneous marketing strategy.

For 3 weeks in Mar. 1987, Pennsylvania floral consumers (401) were interviewed by a professional telemarketing firm. The sample was developed in six steps: 1) stratification by geographic region, 2) selection of telephone directories, 3) random selection of names from each telephone directory, 4) stratification by gender, 5) exclusion of nonpurchasers from the sample, and 6) exclusion of minors (under 18 years).

After the questionnaire was developed and tested, a minimum of 400 respondents was determined to be needed for statistical purposes. This sample was then divided into 300 urban and 100 rural residents. Interviewers selected the prescribed number of respondents from each telephone directory. Even though many potential respondents refuse to participate in surveys, the response rate tends to be sufficiently high to overcome bias in sampling and assure that participation is random (Dillman, 1978).

The sample was further stratified by gen- 
Table 1. Means (SD) and univariate F-ratio significance levels for 18 discriminant variables for light, medium, and heavy user segments for floral products.

\begin{tabular}{lcccc}
\hline \hline & \multicolumn{3}{c}{ Type of user } & \\
\cline { 2 - 4 } Variable & $\begin{array}{c}\text { Light } \\
(\mathrm{n}=65)\end{array}$ & $\begin{array}{c}\text { Medium } \\
(\mathrm{n}=109)\end{array}$ & $\begin{array}{c}\text { Heavy } \\
(\mathrm{n}=82)\end{array}$ & $\begin{array}{c}\text { Significance } \\
\text { level }\end{array}$ \\
\hline No. floral magazine & 0.68 & 0.58 & 1.48 & $0.0122^{*}$ \\
articles read & $(1.03)$ & $(0.95)$ & $(3.53)$ & \\
No. horticultural books & 1.18 & 2.11 & 3.44 & $0.0206^{*}$ \\
owned & $(2.40)$ & $(5.18)$ & $(5.94)$ & \\
No. blooming plants in & 2.98 & 3.94 & 6.07 & $0.0200^{*}$ \\
home & $(4.30)$ & $(5.63)$ & $(13.08)$ & \\
Proportion of users with cut & 0.11 & 0.18 & 0.39 & $0.0001^{*}$ \\
flowers in homc & $(0.31)$ & $(0.39)$ & $(0.49)$ & \\
Consumer rating of floral & 4.38 & 4.21 & 5.11 & $0.0213^{*}$ \\
knowledge & $(2.13)$ & $(2.29)$ & $(2.32)$ & \\
Proportion of users who & 0.25 & 0.37 & 0.59 & $0.0001^{*}$ \\
organized party & $(0.43)$ & $(0.48)$ & $(0.50)$ & \\
Proportion of purchases made & 0.75 & 0.39 & 0.21 & $0.0001^{*}$ \\
from florist & $(0.66)$ & $(0.30)$ & $(0.18)$ & \\
Proportion of purchases made & 0.96 & 0.51 & 0.22 & $0.0001^{*}$ \\
as gift & $(0.74)$ & $(0.24)$ & $(0.18)$ & \\
Proportion of cut-flower & 0.47 & 0.58 & 0.57 & 0.0622 \\
purchases & $(0.43)$ & $(0.29)$ & $(0.29)$ & \\
Avg amount spent/floral & 22.79 & 17.42 & 11.58 & $0.0077^{*}$ \\
purchase (\$) & $(29.71)$ & $(19.39)$ & $(15.85)$ & \\
Education (years) & 13.37 & 13.37 & 13.91 & 0.1815 \\
& $(2.17)$ & $(2.22)$ & $(2.20)$ & \\
Age (years) & 46.02 & 45.16 & 44.54 & 0.8591 \\
& $(17.75)$ & $(16.42)$ & $(14.37)$ & \\
Proportion of females & 0.72 & 0.72 & 0.77 & 0.6992 \\
& $(0.45)$ & $(0.45)$ & $(0.42)$ & \\
Household income in 1986y & 25.38 & 27.66 & 31.21 & $0.0132^{*}$ \\
(thousands dollars) & $(12.15)$ & $(11.49)$ & $(10.10)$ & \\
Proportion of users & 0.40 & 0.49 & 0.63 & $0.0143^{*}$ \\
employed outside home & $(0.49)$ & $(0.50)$ & $(0.48)$ & \\
\hline F & & &
\end{tabular}

${ }^{\mathrm{z} F}$ test evaluated at 2214 degrees of freedom.

${ }_{\mathrm{F}} \mathrm{F}$ score calculated on 52,91 , and 74 observations.

*Significant at $\alpha<0.05$.

Table 2. Standardized discriminant function coefficients from the discriminant analysis for light, medium, and heavy consumer segments.

\begin{tabular}{lcc}
\hline \hline & \multicolumn{2}{c}{$\begin{array}{c}\text { Standardized discriminant } \\
\text { function coefficients }\end{array}$} \\
\cline { 2 - 3 } Variable & Function $1^{z}$ & Function $2^{\mathbf{y}}$ \\
\hline No. floral magazine articles read & 0.17 & 0.47 \\
No. horticultural books owned & 0.05 & -0.40 \\
No. blooming plants in home & 0.17 & 0.13 \\
Proportion of consumers with cut flowers in home & 0.24 & 0.40 \\
Rating of floral knowledge & 0.17 & 0.40 \\
Proportion of consumers who organized party & 0.21 & 0.16 \\
Proportion of purchases made from florist & 0.28 & 0.41 \\
Proportion of purchases made as gift & -0.64 & 0.25 \\
Proportion of cut-flower purchases & 0.25 & -0.40 \\
Avg amount spent/purchase & 0.15 & -0.23 \\
Education (years) & 0.17 & 0.07 \\
Age (years) & 0.11 & 0.19 \\
1986 household income & 0.17 & 0.05 \\
Proportion of females & -0.06 & 0.03 \\
Proportion of consumers employed outside home & 0.17 & 0.05 \\
\hline
\end{tabular}

Function 1: $\chi^{2}=116.30 ; 36 \mathrm{df}$; significance $=0.0000$; Canonical correlation $=0.63$; Eigenvalue $=0.65 ;$ Wilk's lambda $=0.57$. Group centroids: Light users $(-1.20)$, Medium users $(-0.07)$, Heavy users (0.93).

yFunction 2: $\chi^{2}=13.25 ; 17 \mathrm{df}$; significance $=0.7192$; Canonical correlation $=0.25$; Eigenvalue $=$ 0.07 ; Wilk's lambda $=0.94$.

der to include a minimum of 100 men. When the quota for men from each directory had been achieved, the interviewer asked to survey a female from the next household called.

Only buyers of fresh flowers and flowering plants during the previous year participated in the survey.

Information on 106 variables was collected. Three groups of variables were used in these analyses: floral knowledge, past floral purchases, and demographic characteristics.

Six questions measured floral knowledge: 1) the number of magazine articles about flowers and plants they had read within the previous month, 2) the number of horticulture books they owned, 3) the number of blooming house plants they had in their homes at the time of the interview, excluding foliage house plants, 4) whether fresh flowers were in the home at the time of the interview, 5) rating of their knowledge of flowers and plants on a scale from 1 to 10 , and 6) consumers who had organized a party in the previous year.

Floral purchases were measured in a series of questions pertaining to floral purchases made in the previous year. Questions were structured to determine if a floral purchase had been made on each of six holidays and four specific nonholiday occasions. If a purchase had been made, questions were asked to investigate those specific floral purchases. The number of purchases made from a florist shop was calculated from the holiday and occasion purchase information. The purpose of the purchase was recorded to determine if the floral purchase was made for personal or gift use. The type of product purchased was recorded as either fresh flowers or flowering plants. Consumers were asked to indicate, in whole dollars, how much had been spent on each purchase, then the average amount spent per purchase was calculated.

Five items related to demographic characteristics were gathered at the end of the survey: years of education, age, gender, employment outside the home, and household income.

In the first data analysis, consumers were grouped according to the total number of floral purchases they had made over the past year. Respondents were grouped into three consumer segments as light users (one to three floral purchases); medium users (four to eight floral purchases); and heavy users (nine or more floral purchases). These categories were established from an examination of the distribution of floral purchase frequencies.

In the second data analysis, consumers were grouped according to the type of store (florist or supermarket) from which more than half of their floral purchases were made in the previous year.

Consumer groups were separated by discriminant analysis. Discriminant analysis is a statistical method that produces one or more discriminant functions that describe the relationship between two or more mutually exclusve groups (Bull and Dormer, 1987; Dillon and Goldstein, 1984; Klecka, 1981; Morrison, 1969; Norusis, 1985; Peterson, 1982).

Heavy floral users read the most magazine articles related to flowers and plants in the previous month (Table 1). Light and medium floral users read nearly one magazine article less than heavy users. Heavy users also: owned more books on horticulture than medium and light floral users; had nearly twice as many blooming plants in the home as light users; were more likely to have fresh flowers in their homes than either medium or light users; and more likely had organized a party when compared with medium and light users.

Heavy users rated their personal floral knowledge higher than light and medium consumers. Medium-1evel floral consumers read fewer magazine articles than light consumers but owned more horticultural books than the light consumer segment. Medium 
Table 3. Comparison of florist and supermarket customer group means of 15 discriminant variables.

\begin{tabular}{|c|c|c|c|}
\hline Variable & $\begin{array}{c}\text { Florist } \\
\text { customers }\end{array}$ & $\begin{array}{c}\text { Supermarket } \\
\text { customers }\end{array}$ & $\begin{array}{c}\text { Significance } \\
\text { level }\end{array}$ \\
\hline $\begin{array}{l}\text { No. horticultural magazine } \\
\text { articles read }(n=306, n=44)\end{array}$ & $\begin{array}{c}1.32 \\
(6.16)\end{array}$ & $\begin{array}{c}1.45 \\
(3.07)\end{array}$ & 0.818 \\
\hline $\begin{array}{l}\text { No. horticultural books } \\
\text { owned }(n=306, n=44)\end{array}$ & $\begin{array}{c}2.39 \\
(4.70)\end{array}$ & $\begin{array}{c}1.80 \\
(2.33)\end{array}$ & 0.180 \\
\hline $\begin{array}{l}\text { No. blooming plants in } \\
\text { home }(n=306, n=44)\end{array}$ & $\begin{array}{c}5.14 \\
(12.16)\end{array}$ & $\begin{array}{c}4.75 \\
(6.54)\end{array}$ & 0.747 \\
\hline $\begin{array}{l}\text { Proportion of consumers with cut } \\
\text { flowers in home }(n=305, n=43)\end{array}$ & $\begin{array}{c}0.22 \\
(0.42)\end{array}$ & $\begin{array}{c}0.19 \\
(0.39)\end{array}$ & 0.585 \\
\hline $\begin{array}{l}\text { Floral knowledge rating } \\
(\mathrm{n}=306, \mathrm{n}=44)\end{array}$ & $\begin{array}{c}4.47 \\
(3.01)\end{array}$ & $\begin{array}{l}5.11 \\
(2.45)\end{array}$ & 0.178 \\
\hline $\begin{array}{l}\text { Proportion of consumers who organized } \\
\text { party }(\mathrm{n}=294, \mathrm{n}=44)\end{array}$ & $\begin{array}{c}0.42 \\
(0.49)\end{array}$ & $\begin{array}{c}0.32 \\
(0.47)\end{array}$ & 0.196 \\
\hline $\begin{array}{l}\text { Proportion of purchases that } \\
\text { were gift }(\mathrm{n}=306, \mathrm{n}=44)\end{array}$ & $\begin{array}{l}0.55 \\
(0.47)\end{array}$ & $\begin{array}{l}0.35 \\
(0.34)\end{array}$ & $0.001^{*}$ \\
\hline $\begin{array}{l}\text { Avg amount spent/purchase } \\
(\mathrm{n}=306, \mathrm{n}=44)\end{array}$ & $\begin{array}{c}19.75 \\
(23.82)\end{array}$ & $\begin{array}{c}6.86 \\
(5.71)\end{array}$ & $0.001^{*}$ \\
\hline $\begin{array}{l}\text { No. cut flower purchases } \\
(\mathrm{n}=306, \mathrm{n}=44)\end{array}$ & $\begin{array}{c}6.05 \\
(9.50)\end{array}$ & $\begin{array}{l}3.70 \\
(5.98)\end{array}$ & $0.029^{*}$ \\
\hline $\begin{array}{l}\text { No. potted plant purchases } \\
(\mathrm{n}=306, \mathrm{n}=44)\end{array}$ & $\begin{array}{c}4.13 \\
(6.55)\end{array}$ & $\begin{array}{c}4.77 \\
(4.13)\end{array}$ & 0.380 \\
\hline $\begin{array}{l}\text { Education (years) } \\
\qquad(\mathrm{n}=304, \mathrm{n}=44)\end{array}$ & $\begin{array}{l}13.75 \\
(2.22)\end{array}$ & $\begin{array}{l}12.59 \\
(2.20)\end{array}$ & $0.002^{*}$ \\
\hline $\begin{array}{l}\text { Age (years) } \\
\qquad(\mathrm{n}=296, \mathrm{n}=43)\end{array}$ & $\begin{array}{c}44.13 \\
(15.74)\end{array}$ & $\begin{array}{l}47.70 \\
(16.93)\end{array}$ & 0.198 \\
\hline $\begin{array}{l}\text { Proportion who are women } \\
(\mathrm{n}=306, \mathrm{n}=44)\end{array}$ & $\begin{array}{c}0.73 \\
(0.44)\end{array}$ & $\begin{array}{c}0.86 \\
(0.35)\end{array}$ & $0.027^{*}$ \\
\hline $\begin{array}{l}1986 \text { household income (thousands) } \\
(n=244, n=36)\end{array}$ & $\begin{array}{c}28.79 \\
(11.50)\end{array}$ & $\begin{array}{c}24.86 \\
(11.04)\end{array}$ & 0.053 \\
\hline $\begin{array}{l}\text { Proportion of consumers employed } \\
\text { outside home }(\mathrm{n}=303, \mathrm{n}=43)\end{array}$ & $\begin{array}{c}0.55 \\
(0.50)\end{array}$ & $\begin{array}{c}0.21 \\
(0.43)\end{array}$ & $0.001^{*}$ \\
\hline
\end{tabular}

${ }^{2}$ Mean for the consumer segment, and in parentheses, SD.

ySample size for florist and supermarket customer segments, respectively.

*Significant at $\alpha<0.05$.

Table 4. Standardized discriminant function coefficients for 13 discriminant variables that distinguish between the market segments for florist and supermarket customers, excluding average amount of purchase and household income.

\begin{tabular}{lc}
\hline \hline Variable & $\begin{array}{c}\text { Standardized discriminant } \\
\text { function coefficients }\end{array}$ \\
\hline No. floral magazine articles read & 0.03 \\
No. horticultural books owned & 0.23 \\
No. blooming plants in the home & 0.06 \\
Proportion of consumers with cut flowers in home & 0.06 \\
Rating of floral knowledge & 0.24 \\
Proportion of consumers who organized party & 0.07 \\
No. cut flower purchases & 0.28 \\
No. potted plant purchases & 0.02 \\
Proportion of purchases made as gift & 0.52 \\
Education (years) & 0.14 \\
Age (years) & 0.06 \\
Proportion of females & 0.10 \\
Proportion of consumers employed outside home & 0.49 \\
\hline
\end{tabular}

${ }^{2} \chi^{2}=44.22,16 \mathrm{df}$, significance $=0.0001$. Canonical correlation $=0.36$, Eigenvalue $=0.15$, Wilk's lambda $=0.86$. Florist customers: $n=283$, Supermarket customer: $n=41$. Group centroids: supermarket customers $(-1.02)$; florist customers $(0.15)$.

floral consumers owned an average of four blooming plants, $\approx 30 \%$ more than the light consumer segment and $\approx 30 \%$ fewer than the heavy consumer segment. Their rating for floral knowledge was slightly lower than that of the light consumer group. Heavy users may have rated their knowledge higher because they felt more confident in their floral knowledge and had a greater number of experiences than others.

Light consumers made a high percentage of their floral purchases at a traditional florist, while medium consumers made less than half of their total floral purchases there. Heavy consumers made even fewer purchases from priced purchases were for personal rather than for gift use.

Heavy floral consumers came from households with higher incomes and were more often employed outside the home.

The first discriminant function was significant (Table 2). The three largest coefficients were examined to describe the function (Rummel, 1970). The proportion of purchases made as gifts was the largest standardized canonical coefficient and negatively related to the function. The proportion of purchases made from a florist was negatively related to the function, and the percentage of total purchases that were fresh flower products was positively related to the first discriminant function. Thus, it was labeled as a continuum from florist/gift purchases to supermarket/personal-use purchases.

The second discriminant function produced was not significant (second column, Table 2). Since only the first function was significant, the evaluation of the group centroids was made on only one function. Group centroids were -1.20 for light users, -0.07 for medium users, and 0.93 for heavy users.

Significant differences were found for six of 15 variables used to compare supermarket and florist customer groups (Table 3 ). There were no significant differences between florist and supermarket customer group means for the six floral knowledge variables. Both consumer segments read the same number of horticultural magazines per month, owned two horticultural books, had the same number of blooming plants, rated their floral knowledge similarly, and had a similar proportion of consumers organize a party. Twenty percent of florist and supermarket customers had some kind of fresh flowers in the home.

The group means for the past floral purchase variables exhibited three differences. Of the purchases made by florist customers, $55 \%$ were for use as gifts compared with $35 \%$ of those made by the supermarket purchasers. On average, florist customers spent more per floral purchase and purchased more fresh flowers than supermarket customers. Both groups purchased the same number of blooming plants.

The florist customer segment appeared to be slightly more affluent than the supermarket customer segment. More supermarket customers were women than florist customers. Supermarket customers had slightly fewer years of education than florist customers, and fewer supermarket customers were employed outside the home $(21 \%)$ than florist customers $(55 \%)$.

Since the data from a large percentage of the survey respondents had one or more missing variables, a second discriminant analysis was conducted using 13 of the original 15 variables. The average amount per floral purchase and household income were omitted from the second analysis, since missing responses on these two variables accounted for 130 deleted cases. The second discriminant analysis was conducted on 324 cases.

The multivariate discriminant results from the second analysis showed that the function 
was significant (Table 4). The three largest standardized discriminant function coefficients used to describe the function were the proportion of floral purchases made as a gift, the proportion of consumers employed outside the home, and the number of cut-flower purchases. These changes indicated that the missing observations were nonrandomly missing from the first analysis. The centroids for the two groups were - 1.02 for supermarket customers and 0.15 for florist customers.

Although florist and supermarket customers were similar in their floral knowledge, the groups were substantially different in their floral purchase behavior and demographic characteristics. Florist patrons bought flowers somewhat more frequently than supermarket patrons, and many of these purchases were used as gifts, and, as such, a larger amount per purchase was spent on the floral product.

The fundamental differences between light, medium, and heavy floral consumers were location of purchase and intended use of the flowers. Light consumers bought from a florist, and the flowers were intended as a gift; medium consumers bought less often from a florist, and more for personal use; heavy consumers frequently purchased from nontraditional florists, and made many purchases of floral products for their personal enjoyment.

The univariate and multivariate discriminant analyses suggest that florist and supermarket customers were two distinct consumer segments and may respond to separate marketing strategies. Differences between florist and supermarket customers were mainly in the type of floral purchases they made and in their demographic characteristics.

Supermarket floral management might stress value that combines convenience and relatively low prices. In addition, a supermarket strategy that focuses on the service and gift needs of florist customers could generate sales within supermarkets from florist customers who see their service and quality needs being satisfied in their supermarket, and perhaps at a lower price than at a florist shop.

The florist's marketing strategy should be based on consistently high quality and many unique services with a concern for customer shopping convenience. The florist customer spent nearly $\$ 20$ per purchase, but the supermarket customer spent less than $\$ 7$. Supermarket customers purchase a similar number of plants when compared to florist customers but make fewer fresh flower purchases. The florist customer may demand extra services and be more willing to pay for them than the supermarket customer. Convenience and time savings can be stressed to others on a limited time budget in the florist's marketing strategy.

Nontraditional retailers, such as supermarkets, could concentrate on expanding floral sales rather than on directly competing with traditional retailers. Supermarkets could target light and medium floral users to demonstrate that flowers are not necessarily expensive gifts.

The differences between florist and supermarket customers can be reduced conceptually to differences in who performs functions in the market channel. Kotler (1984) stated that the functions performed by members in the channel (i.e., pricing, assortment, delivery, etc.) are always present in the channel, yet they might be shifted from one member to another. Florists provide the selection, design, delivery, and perhaps credit. These services save time for the customer, but cost money. The supermarket offers an alternative, trading dollar cost for time by shifting functions to the customer. Many supermarkets do not offer the functions of selection, design, delivery, and credit. The price of the product is lower, yet the customer's purchasing time commitment may be increased. Since functions in the marketing channel can only shift and not disappear, the customer must perform the functions omitted by the supermarket.

This research provided evidence that an increased number of floral purchases did not depend on increased income but on the intended use of the purchase. Frequent purchasers of floral products buy more floral products for their own use than as gifts. They are more likely to purchase from supermarkets and spend less per purchase, yet they spend more than one and a half times as much for floral products on an annual basis as medium purchasers and four times as much as light purchasers.

Future research should focus on the in- tended use of the floral purchase and how decisions are made about the type of retailer selected, the type of product purchased, the method of payment, and the use of services related to floral products.

\section{Literature Cited}

Behe, B.K. 1985. A market segmentation of supermarket floral product consumers based upon factors impacting the floral purchase decision. MS Thesis. The Ohio State Univ., Columbus.

Bull, S.B. and A. Dormer. 1987. The efficiency of multinomial logistic regression compared with multiple group discriminant analysis. J. Amer. Stat. Assn. 82:1118-1122.

Dillman, D.A. 1978. Mail and telephone surveys: the total design method. Wiley-Interscience Publ. New York.

Dillon, W.R. and M. Goldstein. 1984. Multivariate analysis: methods and applications. Wiley, New York.

Goldsberry, K. L., N. Baker, and M. Michaels. 1985. Determining the desires of supermarket cut flower customers: a six year evaluation. Colorado Agr. Expt. Sta. Res. Bul. 421.

Kelley, R.T., Inc. 1983. Flowers Canada Ontario. Consumer research: Final results. Ohio Agr. Expt. Sta., Wooster.

Kiplinger, D.C. and R.W. Sherman. 1962. Florist crops for mass market outlets. Ohio Agr. Expt. Sta. Res. Bul. 928.

Klecka, W.R. 1981. Discriminant analysis. Quantitative applications in the social sciences series. Sage Publ. Beverly Hills, Calif.

Kotler, P. 1984. Marketing management: Analysis, planning and control. Fifth ed. PrenticeHall, Englewood Cliffs, N.J.

Market Facts. 1985. Society of American florists floral marketing report. Washington, D.C.

Miller, M.N. 1977. Consumer preferences for and attitudes toward cut flower items in supermarkets. M.S. Thesis, Purdue Univ., West Lafayette, Ind.

Morrison, D.G. 1969. On the interpretation of discriminant analysis. J. Mktg. Res. 156-163.

Norusis, M.J. 1985. SPSS ${ }^{\mathrm{x}}$ advanced statistics guide. McGraw-Hill, Chicago.

Peterson, R.A. 1982. Marketing research. Business Publications, Piano, Texas p. 539-542.

Robertson, J.L. and D.E. Hahn. 1978. Analysis of demand for potted chrysanthemums in supermarkets. J. Amer. Soc. Hort. Sci. 103(2):203-206.

Rummel, R.J. 1970. Applied factor analysis. Northwestern Univ., Evanston, 111. p. 477.

Zawadzki, M. I., W.E. Larmie, and A.L. Owens. 1960. Selling flowers in supermarkets. Rhode Island Agr. Expt. Sta. Res. Bul. 355. 